\title{
EFL Reading Metacomprehension from the Developmental Perspective: A Longitudinal Case Study
}

\author{
Renata Šamo \\ University of Zagreb
}

\begin{abstract}
Correspondence concerning this article should be addressed to Renata Šamo, Faculty of Teacher Education, University of Zagreb, Savska cesta 77, Zagreb, Croatia, 10000.E-mail: renata.samo@ufzg.hr
\end{abstract}

\author{
Alenka Mikulec \\ University of Zagreb
}

\begin{abstract}
Correspondence concerning this article should be addressed to Alenka Mikulec, Faculty of Teacher Education, University of Zagreb, Savska cesta 77, Zagreb, Croatia, 10000. E-mail: alenka.mikulec@ufzg.hr
\end{abstract}

\begin{abstract}
As the first half of the literacy equation (reading + writing = literacy), reading is primarily considered a dynamic meaning-focused interaction in which the reader is required to build comprehension of a text in a non-linear way. In other words, the reader is constantly checking the degree to which he or she understands the given information, simultaneously trying to identify comprehension failures and employ efficient repair strategies. This ability is termed metacomprehension; when it is enhanced, comprehension is generally more successful. Metacomprehension appears to be even more important for non-native readers because of their limited vocabulary and grammar. This is the key theoretical background of the single case study described in the current paper since it follows the developmental path of an EFL learner (Croatian teenager) with special focus on his reading ability. The main aim of the study was to see how his metacomprehension would develop over an extended period of exposure to EFL in the school setting. It was based on the hypothesis that extended exposure would result in better awareness of comprehension during the reading process. The study was conducted in two parts (Grade 5 and Grade 8) and comprised a number of stages. Being a case study, multiple sources and techniques were applied in gathering data, both qualitative and quantitative, such as: a multiple-choice comprehension test, a questionnaire for measuring the reader's awareness of strategic reading processes (in Grade 5), an English proficiency test, a text restoration task, the self-revelation (stream-of-consciousness data) technique, a post-reading interview, and observation notes (in Grade 8). The results obtained initially indicated the participant's good EFL reading comprehension performance but later showed that he was less successful, which was related to his poor EFL proficiency. In terms of reading strategy, it can be added that, despite some initial strategic abilities, the participant did not significantly develop his strategic behaviour for EFL reading. To conclude, prolonged exposure to EFL did not lead to better reading metacomprehension in this particular school learner.
\end{abstract}

Keywords: metacomprehension, dynamic system, case study, reading strategies, EFL reading

Reading includes different processes, from the recognition of graphemes to the integration of global ideas from the text into the reader's knowledge. Word recognition, syntactic analysis and text comprehension are most commonly identified as three processing levels that determine an individual's ability to read (Adams, 1999; Beech \& Colley, 1984; Grabe,
2009). Many scholars (see more in Tracey \& Mandel Morrow, 2006) have tried to explain how these are inter-related in terms of their functionality, which has resulted in the determination of the following three broad categories: (a) bottom-up processing (a focus on constructing the text from decoding the smallest units - letters, words, phrases, sentences, etc.); (b) top- 
down processing (an emphasis on fitting the text into the reader's linguistic and non-linguistic knowledge - a sort of psycholinguistic guessing game); and (c) interactive processing (the alternate or simultaneous use of both bottom-up and top-down processing - a dynamic interactive process). It is impossible to avoid any of the three approaches (generally termed models) in serious discussions of the process of reading, particularly when a non-native (both L2 and FL) reader is included (Aebersold \& Field, 1997).

More recently, reading has been explained as a dynamic meaning-focused interaction, so that LarsenFreeman and Cameron, for instance, see this process as:

[a] complex dynamic system moving across a state space landscape that consists of all possible interpretations of the stretch of text being processed. Understanding the whole text is also seen as a complex dynamic system that produces the multidimensional state space landscape on which the reading process moves. The experience of reading the text changes the landscape as the reading process co-adapts with current understandings of the whole text. Meaning is constructed from the text at different levels using the reader's previous experiences of literacy, of texts, and of the world; the reader searches for a coherent meaning for the whole as the parts are processed (2008, pp. 186-187).

Based on the first two types of processing, the building of comprehension is linear, determined by smaller (below sentence level) or larger (above sentence level) pieces of text. The interactive approach, by contrast, implies the non-linear building of comprehension during which the reader is moving from one way of processing to the other. While doing this, he/she is constantly checking his/her comprehension, which is known as self-monitoring. In order to do this efficiently, he/she needs a range of strategies. It is clear that successful reading requires the reader's awareness of his/her comprehension or lack of it, as well as the knowledge of what to do when he/she fails to comprehend (Grabe, 2009).

Metacomprehension as the key term in this paper, therefore, can be defined as the reader's ability to monitor the degree to which he/she understands information being communicated to him/her, to recognise failures to comprehend, and to employ repair strategies when failures are identified. ${ }^{1}$ Efforts to enhance this ability should gradually lead to improved reading comprehension. Unlike grammar, vocabulary knowledge or other competencies important in reading, metacomprehension cannot be developed

\footnotetext{
${ }^{1}$ Adapted from www.cognitiveatlas.org/concept/

metacomprehension.
}

through rote-memorisation, drilling or one-way instruction from the teacher, but requires interaction between the teacher and learners (Cohen \& Weaver, 2006; Yu-Fen, 2002). As Vygotsky (2012) put it, learners acquire the capacity for self-regulation throughout interaction with more knowledgeable individuals. Since the early 1990s, researchers have examined performances in comprehension monitoring between proficient and less proficient readers to discover how metacomprehension can function more effectively (see more in Yu-Fen, 2002). They generally concluded that less proficient readers in the (non-)native language are more likely to fail to recognise that a problem exists or to identify the source and solve it. Even when they are aware of the source of the problem, they find it hard to identify a solution. Speaking explicitly about reading in a non-native language, it may be important to emphasise here that metacomprehension seems to be crucial primarily because the reader possesses limited vocabulary knowledge and grammar (Block, 1992).

The ability to monitor comprehension has also received some attention in reading tasks with young learners. Markman (1979) was among the first researchers to consider this issue and showed, among other things, that children fail to report logical inconsistencies in textual material. According to Grabe (2009), a review of 20 studies with native readers in second to sixth grades who were taught directly how to monitor their comprehension revealed significant improvements in three areas: the detection of textual difficulties, the enhancement of text material recall, and better performance on standardised reading comprehension tests. However, the author adds that the impact of self-monitoring on reading comprehension with non-native readers is still under-represented in research.

This article, therefore, can be seen as a contribution to this field of investigation, while its developmental perspective makes our study, conducted in the context of reading in English as a foreign language (EFL), even more multifaceted. This coincides with Geva and Ramírez (2015) who view EFL reading comprehension as a complex process, pointing out its multiple facets that may change with development and experience.

The main aim of the study was to obtain insight into an individual's development of reading metacomprehension over an extended period of exposure to EFL in the school setting. It was realised by means of the following research question: What, if any, is the effect of extended exposure to EFL on a school learner with regard to his awareness of comprehension during the reading process? The hypothesis was that extended exposure would lead to better awareness of comprehension during the reading process. 


\section{Methods}

Research design. This article reports on an individual or single case study (Benatti, 2015; Robson, 2002; Wei \& Moyer, 2008) used as a research method to understand the effect of extended exposure to EFL on the reading metacomprehension of a male learner. By definition, a case study of this type tends to provide a detailed account of one person (a case) within a wider context. It typically involves multiple techniques of data collection, both quantitative and qualitative, although such an in-depth investigation - which can be done over any length of time - often uses the latter rather than the former. In this particular study, a mixed approach was applied, with eight different types of sources: a questionnaire for measuring a child's awareness of strategic reading processes, a reading comprehension test, an open-ended strategy use questionnaire, a language proficiency test, gap-filling tasks, the self-revelation (stream-of-consciousness data) method, an interview, and notes resulting from online observations.

Participant's profile. Although a large-scale study was conducted with Frank's class, special attention was paid to Frank (not his real name) here, differing him from classmates because of his truly specific linguistic background. Frank was born in a medium-sized city in Croatia, to which his parents, both of Albanian origin, had come from Kosovo in their youth (mother at age 12, father at age 19). He is the third-born child in a family of four children. Asked about his native language, he perceived himself as bilingual and could not say which of the two languages was dominant, since he spoke mostly Albanian with his parents and elderly family members, but used Albanian and Croatian almost interchangeably in communication with his brothers. When unable to remember a word or phrase in Albanian, he would frequently replace it with its Croatian equivalent and vice versa. In his play with other children (both Croatian and Albanian) in the neighbourhood, Croatian prevailed. ${ }^{2}$ This language development can, therefore, be seen as an example of additive simultaneous bilingualism (Gardner, 2002; Lambert, 1977).

At the age of six and a half, he first attended a private primary school (Grades 1-3), where he studied EFL, although it was neither official (just one of the extra-curricular activities, not a formal school subject

\footnotetext{
${ }^{2}$ Basically, Albanian was Frank's first language according to the sequence of language acquisition resulting from his family background, but Croatian was also his first language, meaning the main language used for wider communication in his more or less immediate environment, such as the neighbourhood and his school (Jelaska, 2005). The mother tongue will not necessarily be the main or most frequent language used for communication purposes (Byram, 2004, p. 418).
}

with grading) nor intensive (no more than two class periods a week). In Grade 4, he moved to a state primary school, where he was, for no particular reason, placed in a class that had already been learning English for three years, putting him in an unfavourable position compared to his classmates. The class of 22 learners was part of a pilot project ${ }^{3}$ and had started learning EFL in Grade 1 under very favourable conditions: for example, in Grades 1 and 2 they had had four class periods of 45 minutes every week in groups of 11 learners, in a learner-friendly classroom; in Grade 3 they were taught as a whole class, in a larger classroom used for other subjects as well.

In Grade 5 the number of class periods decreased (three instead of four). The learners also experienced two teacher changes, first in Grade 5 and then in Grade 8 (a total of four different teachers in Frank's case). To make this clearer, it should be emphasised that at that time foreign language (FL) teaching in Croatia was officially introduced in Grade 4 (as a compulsory subject at primary school level), so Frank's class appears to have been privileged to participate in the pilot project. Since his hometown is officially a bilingual environment because of the Italian ethnic minority living there, children were encouraged to learn Italian earlier than other (foreign) languages. It was Frank's second FL (his real name is, in fact, Italian) when the study was conducted. Although he also started learning Italian in Grade 1, the official start occurred in Grade 2, as is common in this Croatian region (Istria).

Despite the circumstances described above, Frank's primary school grades in English were quite good (3, $5,5,5,4),{ }^{4}$ but he was better in Italian $(5,5,5,5,5$, $5,4) .{ }^{5}$ He achieved a very similar range in his grades for Croatian $(5,5,5,5,4,4,4,5) .6$ His grade point average was 5.0 throughout his primary education, from Grade 1 to Grade 8. When the first part of the study was conducted, Frank was a fifth-grader, while in its second part he attended Grade 8. Since the first author taught his class English from Grade 1 to Grade 4, she can confirm that Frank was a very intelligent and hard-working boy, always eager to participate in any activity and compete with his classmates, trying to integrate into their group as strongly as possible; it was obvious that he wanted to perform as well as them, better even, in his EFL classes, which sometimes suggested that he felt tense and stressed. Regarding the wider context of Frank's EFL learning experiences and outcomes, he represents an example of the socalled extreme cases (Wei \& Moyer, 2008), usually overlooked in cross-sectional studies.

\footnotetext{
${ }^{3}$ Language Learning for European Citizenship (EC), see more in Mihaljević Djigunović (2015); Vilke (2015).

${ }^{4}$ Croatian grades: from 1 (fail) to 5 (excellent).

${ }^{5}$ Grades 2-8.

${ }^{6}$ Grades 1-8.
} 


\section{Procedure and Instruments}

As has been previously stated, the study was conducted in two parts, each of them comprising a couple of stages preceded by certain preparations. We have decided to present the procedure in three sections: the key preparation-centred details under one sub-heading and the crucial investigation-centred features under two separate sub-headings (see below).

Preparations. A one-week preparatory stage in Grade 5 was conducted with the aim of explaining to Frank at the outset the rationale behind the study and ensuring his willingness to participate. An informal discussion of the following formed an early part of the process: (a) his L1 and L2 (EFL) reading habits and preferences; (b) possible similarities and differences between the two processes; and (c) other closely related issues. A few multiple-choice reading comprehension tasks, first in Croatian and then in English, were later set (with no time limit) to familiarise him with the given test-taking technique. Although spontaneously encouraged to become a strategic thinker, Frank was not explicitly instructed on metacomprehension strategy use.

Prior to the follow-up study, almost three years later, there was another preparatory stage, which also lasted a week and began with Frank being reminded of his previous involvement. He remembered this somewhat vaguely but still agreed to participate without showing any hesitation, confirming our general impression of him as a very curious boy, not afraid to challenge himself. He was first invited to discuss a set of 20 multiple-choice questions that focused on raising children's awareness of the reading process and strategies (Paris, Cross, \& Lipson, 1984). Of course, they were used to provide explanations about what reading strategies are and when and why they are useful, as well as to prepare him to approach concrete text restoration tasks in a strategic manner. Subsequently, he performed a couple of text restoration tasks, without saying what he was thinking/doing. A few days later, Frank was explicitly trained to practise verbalising in parallel with problem solving before he started working on his own. When it was noticed that such practice-focused repetition might be tedious for him, 'the proper study' (his own words) began in order to keep his enthusiasm at the required level.

Grade 5. The study first involved measuring Frank's awareness of strategic reading processes and assessing his text comprehension along with his actual strategy use. The first instrument used was the Metacomprehension Strategy Index (MSI) with 25 multiple-choice items which ask readers about the strategies they could use before, during, and after reading a narrative text. This questionnaire was designed by Schmitt (1990) and aims to assess primary school children's awareness of metacomprehension behaviours that fit into the following categories: (1) predicting and verifying; (2) previewing; (3) purpose setting; (4) self questioning; (5) drawing from background knowledge, and; (6) summarising and applying fix-up strategies. It was translated from English into Croatian for this study and Frank was asked to circle the best answer for each item based on four options. He did this through silent reading, without any time limit. This instrument was targeted at L1 readers and was used here to encourage Frank's thinking about the process as such, according to his Croatian reading experiences, since the first task referred to his Croatian reading comprehension. Two days later, it was followed by a task that checked his comprehension in English.

The second instrument was a reading comprehension test, based on a short narrative text first in Croatian (about a school boy from a village visiting the capital city) and then in English (about a bear visiting mum and her daughters one winter evening), with ten three-option multiple choice questions in each, which assessed explicit and implicit comprehension. The texts were taken from different textbooks for young learners, while the questions were prepared for the purpose of the test and sometimes required serious independent inferences from the reader as certain pieces of information were not directly stated in the text (higher-order processing). In addition, the questions did not always follow the order in which information was presented in the text (reading as a non-linear activity) and did not repeat the same linguistic patterns from the text since vocabulary items and language structures were often changed (a focus on language knowledge), testing Frank's local and global understanding abilities to a greater extent. The selection of the texts and setting of the questions were discussed with his Croatian and English teachers, as their suggestions appeared important to us.

The third instrument, an open-ended questionnaire, included 12 items covering: (a) strategic reading, (b) L1 vs L2 (EFL) reading, and (c) reading selfevaluation (L1 vs EFL). It was designed on the basis of insights into the relevant literature with reference to specific steps in the process of reading the abovementioned texts. Its aim was to show the participant's retrospective reflections on his actual (not supposed) strategy use and/or to clarify his ways of reaching text comprehension, as well as to provide his general approaches to reading in two languages and reveal his reading self-perception. Frank was asked to write his answers in Croatian (no time limit), immediately upon the completion of each comprehension test.

Grade 8 . The study continued with a special focus 
on Frank's strategic reading behaviour in EFL and once again a series of instruments was used. The first instrument was the standardised English proficiency test, ${ }^{7}$ comprising a reading session and a listening and writing session administered a week later. Reading was covered by five matching tasks, as follows: (1) read this short interview from a British youth magazine, match the questions with the answers, e.g. "Fish, smells awful ... - Any food you hate?"; (2) read the following quiz questions and find the right answer, e.g., "It's a way of attracting bees, flies, butterflies and other insects - Why do some flowers smell sweet?"; (3) read the following ads and find the missing part from the list for each gap, e.g., "The Society of London Theatre, the only official half price ticket booth ... - best value for today's evening performances"; (4) find the pairs of these definitions from the list, e.g., "a person you visit if you have a headache or a sore throat - doctor"; and (5) what do these notices mean, choose from the answers, e.g., "return books here - this is the library desk".

Task 3 was the only one that did not contain an extra word. Listening was tested with the help of two matching tasks: (1) listen to the text and put the numbers in the picture in the boxes next to the names (a description of the park with many children doing different things simultaneously); and (2) listen to the text and choose one of the answers (e.g., guessing the locations where the speakers are talking). There was only one writing task, which required the participant to compare two almost identical pictures showing a typical afternoon in a family living room (prompts already given, e.g., write about the man and the woman, the weather outside, etc.).

The second instrument involved three different text restoration tasks, which included 22, 32 and 37 gaps respectively. According to this traditional gapfilling technique, based on short narrative texts, Frank's task was to restore every fifth word that had been deleted (except in the first and last sentences). ${ }^{8}$ These were either content (emphasis on testing the overall text meaning) or function (emphasis on testing grammatical sensitivity) words. He took the tests at irregular intervals over a period of three months.

Since this format predominantly measures comprehension of the local environment (words and immediate constituents, i.e., syntax and lexis at sentence level), it was accompanied with the streamof-consciousness technique (self-revelation). In other words, Frank was instructed on how to verbalise his thoughts (reveal himself) during the text restoration procedure to provide insights into his global text

\footnotetext{
${ }^{7}$ A battery of tests designed by a Hungarian team. See more in: Alderson, Nagy, \& Öveges (2000); Fekete, Major, \& Nikolov (1999).

8 Contextual support to the reader.
}

comprehension as well.

Finally, he was interviewed each time he finished a text restoration task (immediately upon completion). This was a semi-structured interview - a set of questions had been prepared in advance but any interesting, unexpected detail was also discussed with him during the interview. The initial questions regarded: (1) text title (e.g., "What title would you suggest and why?"); (2) text comprehension (e.g., "Did you understand the text/What is it about?"); and (3) comprehension problems (e.g., "Why haven't you filled in this gap/Where did you have a (serious) problem, why?"). As can be seen, these were actually aimed at assessing Frank's abilities to summarise the text in a meaningful title, identify the main ideas, and cope with problem-solving situations in the context of reading. They helped us identify his approaches to understanding words/text portions, test-taking (task format and test-taking environment), and recognising knowledge/self-confidence (or lack of it).

Using the text restoration task and post-reading interview as instruments resulted in rich stream-ofconsciousness reports (audio-recorded), convenient for an in-depth analysis of Frank's strategic behaviour in EFL reading. It could be said that these represented a kind of matrix for his strategy use according to the categorization of processing strategies designed by Anderson, Bachman, Perkins, and Cohen (1991). Appropriate for this context, it comprised: (1) supervising strategies (11 in total, e.g., reading-rate adjustment to increase comprehension, recognition of loss of concentration); (2) support strategies (2 in total, e.g., skipping unknown words, expressing a need for help); (3) paraphrase strategies (5 in total, e.g., use of cognates between L1 and L2 to comprehend, paraphrasing); (4) strategies for establishing coherence in text (7 in total, e.g., rereading, use of background knowledge); (5) other strategies (2 in total, e.g., answer provided with no explanation, change in answer).

\section{Results and Discussion}

The obtained data were analysed quantitatively and qualitatively, and the most important findings are presented according to the sequence in which the instruments were administered following the preparations. We think that this is not only relevant from the structural viewpoint (the two-part study comprising several stages), but also for practical reasons, since it enables us to follow his EFL reading development in a chronological order and, consequently, to get a more precise and comprehensive picture.

Preparations. The week spent on preparing 
Frank for the study in Grade 5 showed, firstly, that he particularly liked the (new) possibility of expressing his opinions without any sort of 'punishment' (every single answer was correct and important), as well as the fact that the given tasks would not be evaluated for school purposes (official grading excluded). During the informal discussion on reading, he presented himself as an experienced reader, motivated to read more frequently in English, despite his awareness that this skill is more demanding and challenging than when practised in Croatian.

The steps taken within preparations in the follow-up study in Grade 8 generally revealed that thinking about reading in a truly process-oriented way seemed quite interesting to him, also suggesting how intrigued he was as a reader. Sessions focused on doing and simultaneously verbalising different reading tasks confirmed that he was very serious and concentrated, trying to do everything correctly, although unfortunately most of the time he repeated the instructor's most frequent comments, obviously rather to please the instructor than to provide details about his thoughts. Many other researchers have also reported this experience in their studies preceded by some type of training, but when our participant was intensively exposed to text restoration, he soon abandoned this practice and became absorbed in his dilemmas, expressing them in his own words.

Analysing the participant's behaviour and reactions during both preparatory phases, we can say that our interaction not only confirmed his genuine interest in discussions on L1 and EFL reading, but also indicated his unquestionable involvement in this longitudinal study, as will be shown below. Indeed, Frank's motivation increased with every step, making him a very desirable study participant.

\section{Grade 5}

Metacomprehension Strategy Index (MSI). As already stated, the first instrument, the MSI, was used to measure the participant's awareness of strategic steps as an introduction to his actual strategy use during the processes of reading and test-taking that followed.

Table 1

Frank's performance on the MSI

\begin{tabular}{ccccccc}
\hline \multicolumn{7}{c}{ MSI Data } \\
\hline P/V & Pre & Pur & Que & B/K & S/FU & Total \\
$(7)$ & $(2)$ & $(3)$ & $(3)$ & $(6)$ & $(4)$ & $(25)$ \\
1 & 2 & 0 & 1 & 1 & 1 & 6 \\
\hline
\end{tabular}

Note: strategy categories: $\mathrm{P} / \mathrm{V}$ - predicting \& verifying; Pre previewing strategies; Pur - purpose setting; Que - self-questioning; $\mathrm{B} / \mathrm{K}$ - drawing from background knowledge; S/FU - summarizing \& applying fix-up strategies.
Table 1 shows that Frank opted for two previewing strategies and one strategy in each of the following categories: predicting and verifying, self-questioning, drawing from background knowledge, and summarising and applying fix-up strategies. None of the purposesetting strategies was selected. Specifically, he thought that in the pre-reading stage it was a good idea to look at the pictures and/or to read the title to see what the story was about, just as it could be helpful to consider what he already knew about the things he saw in the picture. During the while-reading stage, he believed that it was helpful to stop to retell the main points to see if he was understanding what had happened so far, to check to see if he could answer any of the questions he had asked before he started reading, and to check to see whether or not his guesses were correct. Since Frank selected only 6 out of 25 possible responses indicative of metacomprehension, it could be said that his performance on the MSI indicated low strategic awareness.

Reading comprehension task(s). However, Frank's reading test scores suggested that he was skilled in comprehension because he performed so highly on both tasks (Croatian -100\%; English - 90\%). The only mistake found in the English task probably resulted from his lack of concentration, since the correct answer did require a more careful reading to make a valid inference about the weather conditions depicted outside and the atmosphere shown inside. Furthermore, there was a piece of information in the first sentence that could rather easily mislead him into giving his answer without much thought.

Strategy use questionnaire(s). Asked about his steps before, during, and after reading the given texts, Frank mentioned in the questionnaire that he had looked at the questions first and then read both texts once, "at normal pace, silently and carefully", with no difficulties in comprehending them, because there were no unfamiliar words ("I just understood it."). This is probably why he stated that he could answer each question, "easily but carefully ('no problem')", which may confirm him not only as a careful reader, but also as a careful test-taker (see below his text restoration sessions: the same impression).

However, he did not provide any response to the question about the way(s) in which he constructed meaning either in L1 or EFL. Despite his seemingly effortless problem-solving in the given situation, he perceived EFL reading as a difficult task when compared to L1 reading, since English is a foreign language which is - according to him - enough to make the process more demanding, although he thought that he could read well in English / Croatian regardless of the "many"/ "occasional" mistakes he made. He also explained that it was much easier for him to read in Croatian because of his better-developed speaking 
skills ("since early childhood"), while he mentioned Grade 5 in English to support his high self-evaluation, which indicates that children (especially at primary school age) tend to identify grades with their real knowledge (5 means great knowledge, regardless of the underlying criteria). Finally, when asked which of the two narrative texts he preferred, Frank chose the Croatian one, "because it was more interesting".

Total performance in Grade 5. To sum up his reading achievements in Grade 5, we can say that Frank was seen as good at reading in both Croatian and English. While it is true that he had some strategic abilities, he was not sufficiently aware of them and their use at that time.

\section{Grade 8}

EFL proficiency test. The standardised EFL proficiency test, used first in this part of the study, showed that Frank's performance ranged from $62.5 \%$ for writing skill to $76.8 \%$ for reading comprehension and $80 \%$ for listening comprehension. More precisely, he scored 20 out of 32 points on the writing section, rated by three independent assessors according to: (1) levels of text organisation (a sequence of sentences established but no more than three different sentence types used); (2) task achievement (both pictures A and B described); (3) grammar/accuracy (the whole text comprehensible despite some mistakes); and (4) vocabulary (a good choice of items, mostly appropriate to the task).

With regard to his reading comprehension, he achieved the top score on tasks 1,2 and 4 , whereas for tasks 3 and 5 he scored $44.4 \%$ and $40 \%$ respectively. This may have happened because task 3 included advertisements, which might not have been a part of his reading experience (at least not common in EFL classes) at that age; considering task 5, it may also be concluded that this kind of reading (so-called functional reading in the immediate environment) was not generally encouraged in EFL classes, since narrative texts were dominant in this phase of formal language education. Frank scored best on the listening section, where he selected 8 out of 10 correct responses in both tasks. Considering his results, it can be said that his performance on the EFL proficiency test did not suggest high(er) expectations.

Text restoration task(s) (TRT). Frank's performance on the text restoration tasks was recorded as follows: $53.1 \%$ on TRT $2,50 \%$ on TRT 3 , and $40.9 \%$ on TRT 1 ; that is, his overall comprehension performance was in a low range. Specifically, his response to the three tasks included: (a) 33 restored gaps that were accepted as both syntactically and semantically correct; (b) 24 restored gaps that were accepted as either syntactically or semantically correct; (c) 18 restored gaps that were accepted at neither level; and (d) 16 gaps that were not restored at all. In other words, Frank provided 57 out of 92 expected responses, which put him into the category of less successful EFL readers. This coincides with his EFL proficiency test performance (a lower-achieving EFL learner $=$ a lower-achieving EFL reader) since the type of task employed (deletion of both function and content words) required the reader's grammatical (syntax and morphology), as well as background (lexis) knowledge.

Stream-of-consciousness report(s) (SCR). Frank's SCRs provided precise insights into his strategic behaviour while reading/restoring the three abovementioned texts in English. Firstly, after coding Frank's transcripts, the total number of strategies obtained was $\mathrm{N}=513\left(\mathrm{~N}_{\text {text1 }}=171, \mathrm{~N}_{\text {text2 }}=183, \mathrm{~N}_{\text {text3 }}=159\right)$. It is worth noting that the highest number of strategies was used for reading text 2 related to TRT 2 , on which the best score was recorded.

The frequency of individual strategy use was further considered. As shown in Table 2, the highest individual strategy use was recorded for one of the strategies for establishing coherence (reading ahead), two strategies in the paraphrase category (translating a word/phrase into L1, and paraphrasing), and another two in the supervising category (formulating a question and making a prediction about the meaning of a word or text content).

Since the obtained results also indicate a variety of strategy use, seemingly caused by the given texts, these were analysed accordingly. On the first text, the highest frequency was recorded for one strategy used for establishing coherence (reading ahead), one in the supervising category (formulating a question), and one in the paraphrase category (translating a word/phrase into L1). During the second text reading session, the highest frequency was obtained for two paraphrase strategies (translating a word/phrase into L1 and paraphrasing), and one supervising strategy (making a prediction about the meaning of a word or text content). In the third case, the highest frequency referred to one strategy in the establishing coherence category (reading ahead) and one in the paraphrase category (translating a word/phrase into L1 and paraphrasing).

On the other hand, Table 2 reveals that four strategies had not been applied at all: two supervising strategies (stating success in understanding (a portion of) text; responding affectively to text content), one paraphrase strategy (using cognates between L1 and L2 to comprehend), and one strategy for establishing coherence (relating stimulus sentence to personal experiences).

When this failure is analysed by text, it can be seen that as many as seven strategies were not applied while reading the first text. That is, in addition to the four 
Table 2

Frequency of Individual Strategies Used by the Participant for Each of the Three Texts, and the Total Mean, Minimum and Maximum Values, Standard Deviation, Standard Error, and Coefficient of Variation for Each Strategy

\begin{tabular}{|c|c|c|c|c|c|c|c|c|c|c|c|}
\hline \multirow[b]{2}{*}{ Category } & & \multirow[b]{2}{*}{ Strategy } & \multirow[b]{2}{*}{$\begin{array}{l}\text { text } \\
1 \\
\text { (f) }\end{array}$} & \multirow[b]{2}{*}{$\begin{array}{l}\text { text } \\
2 \\
\text { (f) }\end{array}$} & \multirow[b]{2}{*}{$\begin{array}{l}\text { text } \\
3 \\
\text { (f) }\end{array}$} & \multicolumn{6}{|c|}{ Total for all three texts } \\
\hline & & & & & & M & $\min$ & $\max$ & SD & $\begin{array}{c}\mathrm{SE} \\
\text { mean }\end{array}$ & $\mathrm{CV}$ \\
\hline \multirow[t]{11}{*}{$\begin{array}{l}\text { Supervising } \\
\text { strategies }\end{array}$} & 1. & $\begin{array}{l}\text { Referring to the experimental } \\
\text { task }\end{array}$ & 3 & 3 & 5 & 3.67 & 3 & 5 & 1.15 & 0.67 & 31.49 \\
\hline & 2. & $\begin{array}{l}\text { Recognizing loss of } \\
\text { concentration/memory problem }\end{array}$ & 2 & 3 & 1 & 2.00 & 1 & 3 & 1.00 & 0.53 & 50.00 \\
\hline & 3. & $\begin{array}{l}\text { Stating failure to understand (a } \\
\text { portion of) text }\end{array}$ & 5 & 4 & 6 & 5.00 & 4 & 6 & 1.00 & 0.53 & 20.00 \\
\hline & 4. & $\begin{array}{l}\text { Stating success in } \\
\text { understanding (a portion of) } \\
\text { text }\end{array}$ & $\mathbf{0}$ & $\mathbf{0}$ & $\mathbf{0}$ & 0.00 & 0 & 0 & 0.00 & 0.00 & 0 \\
\hline & 5. & $\begin{array}{l}\text { Adjusting reading style /rate to } \\
\text { increase comprehension }\end{array}$ & 3 & 9 & 3 & 3.33 & 3 & 9 & 0.53 & 0.33 & 6.93 \\
\hline & 6. & Formulating a question & $\underline{22}$ & 16 & 10 & 16.00 & 10 & 22 & 6.00 & 3.46 & 37.5 \\
\hline & 7. & $\begin{array}{l}\text { Making a prediction about the } \\
\text { meaning of a word or text content }\end{array}$ & 9 & $\underline{22}$ & 10 & 13.67 & 9 & 22 & 7.23 & 4.13 & 52.93 \\
\hline & 8. & $\begin{array}{l}\text { Referring to lexical items that } \\
\text { impede comprehension }\end{array}$ & 11 & 16 & 3 & 10.00 & 3 & 16 & 6.56 & 3.79 & 65.57 \\
\hline & & $\begin{array}{l}\text { Confirming/disconfirming an } \\
\text { inference }\end{array}$ & 9 & 5 & 14 & 9.33 & 5 & 14 & 4.51 & 2.60 & 43.31 \\
\hline & 10. & Referring to the previous passage & 1 & $\mathbf{0}$ & $\mathbf{0}$ & 0.33 & 0 & 1 & 0.53 & 0.33 & 173.21 \\
\hline & 11. & $\begin{array}{l}\text { Responding affectively to text } \\
\text { content }\end{array}$ & $\mathbf{0}$ & $\mathbf{0}$ & $\mathbf{0}$ & 0.00 & 0 & 0 & 0.00 & 0.00 & 0 \\
\hline \multirow[t]{2}{*}{ Support strategies } & 12. & Skipping unknown words & 3 & 0 & 4 & 2.33 & 0 & 4 & 2.03 & 1.20 & 39.21 \\
\hline & 13. & $\begin{array}{l}\text { Expressing a need for help/ } \\
\text { clarification }\end{array}$ & 0 & 14 & 4 & 6.00 & 0 & 14 & 7.21 & 4.16 & 120.19 \\
\hline \multirow[t]{5}{*}{$\begin{array}{l}\text { Paraphrase } \\
\text { strategies }\end{array}$} & 14. & $\begin{array}{l}\text { Using cognates between } \mathrm{LI} \\
\text { and } \mathrm{L} 2 \text { to comprehend }\end{array}$ & $\mathbf{0}$ & $\mathbf{0}$ & $\mathbf{0}$ & 0.00 & 0 & 0 & 0.00 & 0.00 & 0 \\
\hline & 15. & Breaking lexical items into parts & $\mathbf{0}$ & 3 & $\mathbf{0}$ & 1.00 & 0 & 3 & 1.73 & 1.00 & 173.21 \\
\hline & 16. & Paraphrasing & 6 & $\underline{21}$ & 15 & 14.00 & 6 & 21 & 7.55 & 4.36 & 53.93 \\
\hline & 17. & $\begin{array}{l}\text { Transiating a word/ } p \text { hrase into } \\
L I\end{array}$ & 13 & $\underline{23}$ & $\underline{21}$ & 20.67 & 13 & 23 & 2.52 & 1.45 & 12.13 \\
\hline & 18. & $\begin{array}{l}\text { Extrapolating from information } \\
\text { in the text }\end{array}$ & 5 & 4 & 2 & 3.67 & 2 & 5 & 1.53 & 0.33 & 41.66 \\
\hline \multirow[t]{7}{*}{ Establishing coherence } & 19. & Rereading & 10 & 1 & 3 & 4.67 & 1 & 10 & 4.73 & 2.73 & 101.27 \\
\hline & 20. & $\begin{array}{l}\text { Using context clues to interpret } \\
\text { a word/phrase }\end{array}$ & 2 & 1 & 0 & 1.00 & 0 & 2 & 1.00 & 0.53 & 100.00 \\
\hline & 21. & $\begin{array}{l}\text { Reacting to author's style or } \\
\text { text surface structure }\end{array}$ & 13 & 5 & 5 & 7.67 & 5 & 13 & 4.62 & 2.67 & 60.25 \\
\hline & 22. & Reading ahead & $\underline{29}$ & 14 & $\underline{21}$ & 21.33 & 14 & 29 & 7.51 & 4.33 & 35.13 \\
\hline & 23. & Using background knowledge & 2 & 1 & 0 & 1.00 & 0 & 2 & 1.00 & 0.53 & 100.00 \\
\hline & 24. & $\begin{array}{l}\text { Acknowledging lack of } \\
\text { background knowledge }\end{array}$ & $\mathbf{0}$ & $\mathbf{0}$ & 2 & 0.67 & 0 & 2 & 1.15 & 0.67 & 173.21 \\
\hline & 25. & $\begin{array}{l}\text { Relating stimulus sentence to } \\
\text { personal experiences }\end{array}$ & $\mathbf{0}$ & $\mathbf{0}$ & $\mathbf{0}$ & 0.00 & 0 & 0 & 0.00 & 0.00 & 0 \\
\hline \multirow[t]{2}{*}{$\begin{array}{l}\text { Other } \\
\text { strategies }\end{array}$} & 26. & $\begin{array}{l}\text { Providing a response without } \\
\text { explaining it }\end{array}$ & 6 & 15 & 15 & 12.00 & 6 & 15 & 5.20 & 3.00 & 43.30 \\
\hline & 27. & Changing an answer & 7 & 3 & 10 & 6.67 & 3 & 10 & 3.51 & 2.03 & 52.63 \\
\hline
\end{tabular}


that have already been mentioned, Frank did not use three more strategies: one support strategy (expressing a need for help/clarification), one paraphrase strategy (breaking lexical items into parts), and one strategy for establishing coherence (acknowledging lack of background knowledge). For the second text, seven unused strategies were also recorded, the four already mentioned plus another three strategies: one supervising strategy (referring to the previous passage), one support strategy (skipping unknown words), and one strategy for establishing coherence (acknowledging lack of background knowledge). Eight strategies went unused for the third text, i.e. four in addition to those already mentioned: one supervising strategy (referring to the previous passage), one paraphrase strategy (breaking lexical items into parts), and two strategies for establishing coherence (using context clues to interpret a word/phrase, and using background knowledge).

Higher standard deviation (SD) values for some of the strategies (e.g. expressing a need for help/ clarification), indicating more dispersed results, and the differences in the mean values suggest very large variation in the use of individual strategies in this single case study, which may explain why some strategies do not fall within the applied strategy categorization. This is also indicated by the coefficient of variation (CV), which represents the ratio of the standard deviation to the mean. As illustrated in Table 2, SDs go as high as $173.21 \%$ of the mean for three strategies (i.e., referring to the previous passage, breaking lexical items into parts, and acknowledging lack of background knowledge), $120.19 \%$ for one strategy (i.e., expressing a need for help/clarification), and around
$100 \%$ for three strategies (i.e., rereading, using context clues to interpret a word/phrase, and using background knowledge). High standard error mean values obtained for paraphrasing, making a prediction about the meaning of a word or text content and expressing a need for help/clarification also indicate deviation from the expected values.

Mean values for strategy use regarding each text and each category were also calculated and compared (see Figure 1). The mean results obtained, for a total of 27 observed strategies, show that Frank's strategy use was fairly low $(M=6.33, \mathrm{SD}=7.10, \mathrm{SE}=0.79)$ with the highest total mean value being 6.78 for the second text.

Therefore, these results, despite indicating lower mean strategy use by Frank and despite this being a single case study, enable useful insight into his strategic behaviour, or lack of it. Since the frequency of some strategies differed from one text to another (e.g. the use of making a prediction about the meaning of a word or text content was $\mathrm{N}=9$ on the first text, $\mathrm{N}=22$ on the second, and $\mathrm{N}=10$ on the third text, or rereading: $\mathrm{N}=$ 10 on the first text, $\mathrm{N}=1$ on the second, and $\mathrm{N}=3$ on the third text), one of the factors that may have affected his strategy use were characteristics of the text he was reading. Also, failure to use some strategies may also have resulted from specific text/content features, i.e. it is possible that Frank acknowledged lack of background knowledge only while reading the third text because the other two did not give him such a possibility. In addition, failure to use certain strategies (e.g. relating stimulus sentence to personal experiences or using cognates between L1 and L2 to comprehend) may have been a consequence of his insufficient knowledge or awareness of these particular strategies.

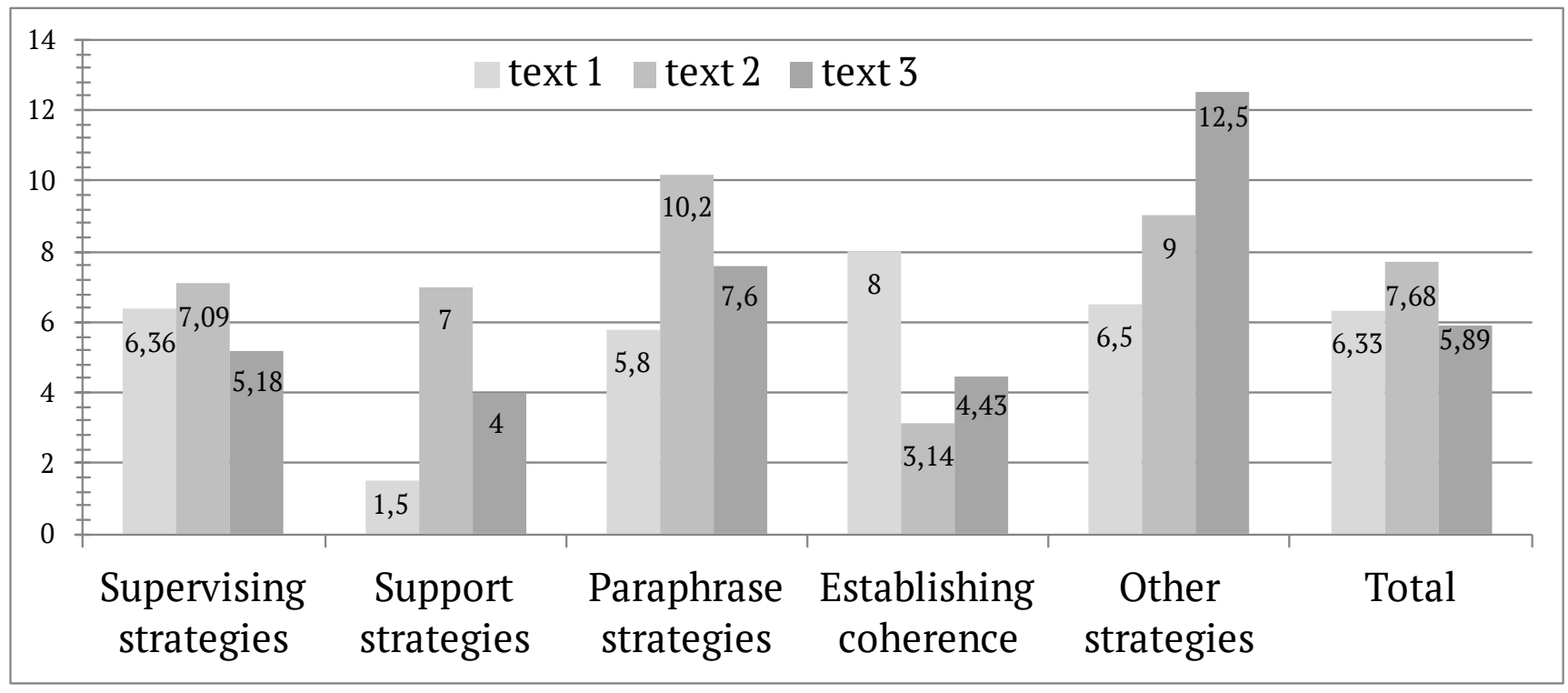

Figure 1. Mean Values for Each Category of Reading Strategies Presented for All Three Texts. 
Post-Reading Interview(s) (PRI) and On-Line Observation(s)

With reference to the final instrument, we can see that PRI 1 supported earlier evidence of Frank's poor performance on TRT 1 since he himself admitted a lack of (particularly key) word knowledge several times (e.g., "Have no idea - these two words ... this is what mostly keeps bothering me!"), so he could not comprehend the text completely (“... actually I don't know what this is all about ...") and, consequently, was not able to suggest any title ("This should be a kind of detective story ... Well, how should I know?! It's difficult (...) again these two words ... they are important here, I guess ..."). His focus on word identification was very obvious and clearly prevented him from making free conclusions about the text at the global level. Asked about the plot, he mostly followed the text by translating, paraphrasing and guessing - sentence after sentence (without summarising the key points). The observational notes additionally reveal that he was anxious, which made him tap his right foot under the desk all the time. Despite his excellent behaviour in the training sessions, his inhibition was recognised during this test-taking session. Based on the general impression, Frank was very systematic when doing the task (sometimes even wasting time on some portions), paid great attention to details (often unnecessarily), approached the task very affectively (lots of sighs, moments of frustration, impatient reactions, etc.) - he was very serious about his involvement in the study and tried to make the most of it.

Next, PRI 3 related to TRT 3, which did not yield great results either, showed a higher level of comprehension ("This is a sort of his autobiography ...") because he suggested the title correctly and expressed his positive feelings about the task itself ("not difficult"), hoping for good results ("At least I think that I knew a lot"). Yet, from time to time, he would mention: "I know what to say but don't know what to write here". He probably meant that he could globally comprehend a particular portion, but had some local problems at the level of writing (spelling) or grammar (part of speech), explicitly referring this specific task to his EFL production abilities. Online observations also indicated that this was still a real problem for him ("This is all I know - can't go on ...”), which he mostly tended to solve again by translating the text into Croatian (this was how he started the task and he continued this way until he had finished it), but his translations frequently made him confused and hesitant, and sometimes even led to frustration (“Oh my God!!”, “What?!”).

PRI 2 considering TRT 2, on which Frank performed 'the best' (see Text restoration task(s) (TRT) above), indicates that he mainly comprehended the text globally despite "many unfamiliar words, indeed"; it seems that he built a wider picture of the story since he provided more inferences rooted in the given context ("This is the most logical solution here.") and his background knowledge ("his tent ... meaning he's camping."). Therefore, he immediately suggested an adequate title but, when asked about his feelings/ experiences on this particular occasion, he was not specific ("don't know what to say"). However, according to the observations, he would grow frustrated and impatient almost every time he could not remember, understand or write something ("What's missing here?!?" "Huh, it's confusing me so much.”), and would also show a lack of confidence. From time to time, he showed an awareness of the excessive attention he was giving to the same problem and its solution(s), which he explicitly mentioned ("Oh my God, I'm constantly focusing on this."); he then tried to solve the problems not only through overusing translations and paraphrasing, but by relying on predictions ("This should be some ...") and asking for help ("What does this word mean?"). Obviously again, he was extremely eager to do the task correctly and properly.

\section{Total Performance in Grade 8}

To sum up, Frank's reading in English at the end of this part was unexpectedly not as successful as it had been in Grade 5, which may be directly related to his proficiency in English. Frank had some abilities that indicated his strategic approach, but he did experience EFL reading as a problem-solving activity in which he tried to focus on both lower-order and higher-order strategies. However, his EFL reading behaviour in Grade 8 was not sufficiently developed to help him to select strategies that could be more efficient in terms of his comprehension capacity.

\section{Conclusion}

Considering the participant's background, we may conclude that his language development was not straightforward, since he was raised in an Albanian language setting deeply immersed in a Croatian language environment, particularly with respect to his formal education experiences and out-of-home personal life. In addition, he was exposed to learning two foreign languages (almost) at the same time, one of which was the second language for a part of the population of the place in which he spent his childhood. Looking specifically at learning English, this occurred under special circumstances, which were not favourable in the participant's case, putting him in a position of constant competition with his classmates who were more advanced and experienced 
when he joined them. However, it must be mentioned that the overall learning conditions were not stable for them as a group either, since they went through several changes. Specifically, they changed teachers, the number of learners in classes, the total amount of class periods and space where the lessons were held, along with all the facilities and aids normally found in a learning/teaching environment. It is quite clear that these are factors of crucial importance for any formal language development, so we suppose that one of the reasons for the results obtained lies in a combination of such linguistic and non-linguistic landscapes (Šamo, 2015).

Based on the findings driven by the given research design, it can be generally concluded that the participant's later EFL reading development represents a true problem-solving process during which he consciously tried to cope with comprehension (and other) problems in the text by using strategies frequently, but with limited scope, although it might be argued that his early reading development and problem-solving processes were not assessed well enough to enable us to draw more reliable comparisons. It suggests that his metacomprehension ability did not develop as anticipated over the extended period. In other words, the effect of extended exposure to EFL in this Croatian school learner was not entirely positive when his awareness of EFL reading comprehension was taken into account (see Šamo, 2009), which disconfirmed our hypothesis. This consequently fits into SLA research findings, which have more recently viewed the question of exposure in "a very wide spectrum of considerations' (Singleton, 2014, p. 33). Age is just one of the factors, highlighting the interactive network of various language development components.

Most studies are subject to certain limitations and ours was no exception. First, since the participant's linguistic picture is rather complex, it might have been useful to assess each language in terms of metacomprehension abilities to set a base line for later assessment comparisons, although it should be mentioned that we focused on his EFL reading in particular, as the title of the current paper clearly shows. Second, the participant could have been given a similar EFL proficiency test in Grade 5 to provide precise insights into interference factors related to his EFL proficiency and metacomprehension reading strategies. Despite these shortcomings, we still believe that the present study can reveal some interesting views of EFL reading metacomprehension development and contribute to the longitudinal mixed-method approach to reading research within SLA.

\section{Acknowledgements}

We would like to thank the anonymous reviewers and Jelena Mihaljević Djigunović for their helpful feedback and suggestions.

\section{References}

Adams, M. J. (1999). Beginning to read: Thinking and learning about print. Cambridge, MA \& London, UK: The MIT Press.

Aebersold, J. A., \& Field, M. L. (1997). From reader to reading teacher: Issues and strategies for second language classrooms. Cambridge, UK: Cambridge University Press.

Alderson, C. J., Nagy, E., \& Oveges, E. (Eds.). (2000). English language education in Hungary, Part II: Examining Hungarian learners' achievements in English. Budapest, Hungary: The British Council Hungary.

Anderson, N., Bachman, L., Perkins, K., \& Cohen, A. (1991). An exploratory study into the construct validity of a reading comprehension test: Triangulation of data sources. Language Testing, 8 , 41-66.

Beech, R. J., \& Colley, A. M. (1990). Cognitive approaches to reading. Chichester, England: John Wiley \& Sons, Ltd.

Benatti, G. A. (2015). Key methods in second language acquisition research. Sheffield \& Bristol, UK: Equinox.

Block, E. L. (1992). See how they read: Comprehension monitoring of L1 and L2 readers. TESOL Quarterly, 26, 319-343.

Byram, M. (Ed.). (2004). Routledge encyclopedia of language teaching and learning. London, UK: Routledge.

Cohen, A., \& Weaver, S. J. (2006). Styles and strategiesbased instruction: A teachers' guide. Minneapolis, MN: Center for Advanced Research on Language Acquisition, University of Minnesota.

Fekete, H., Major, E., \& Nikolov, M. (Eds.). (1999). English language education in Hungary: A Baseline study. Budapest, Hungary: The British Council Hungary.

Gardner, R. C. (2002). Social psychological perspective on second language acquisition. In R. B. Kaplan (Ed.), The Oxford handbook of applied linguistics (pp. 160-169). Oxford, UK: Oxford University Press.

Geva, E., \& Ramírez, G. (2015). Focus on reading. Oxford, UK: Oxford University Press.

Grabe, W. (2009). Reading in a second language: Moving from theory to practice. Cambridge, UK: Cambridge University Press.

Jelaska, Z. (2005). Materinski, drugi, strani i ostali jezici [First, second, foreign and other languages]. 
In Z. Jelaska (Ed.), Hrvatski kao drugi i strani jezik [Croatian as a Second and Foreign Language] (pp. 2437). Zagreb, Croatia: Hrvatska sveučilišna naklada.

Lambert, W. E. (1977). Effects of bilingualism on the individual. In P. A. Hornby (Ed.), Bilingualism: Psychological, Social and Educational Implications (pp. 15-27). New York, NY: Academic Press.

Larsen-Freeman, D., \& Cameron, L. (2008). Complex systems and applied linguistics. Oxford, UK: Oxford University Press.

Lewis, M. (n.d.). Metacomprehension. Retrieved from www.cognitiveatlas.org/concept/ metacomprehension

Markman, E. M. (1979). Realizing that you don't understand: Elementary school children's awareness of inconsistencies. Child Development, 50, 643-665.

Mihaljević Djigunović, J. (2015). Context and structure of the study. In J. Mihaljević Djigunović \& M. M. Krajnović (Eds.), Early Learning and Teaching of English: New Dynamics of Primary English (pp. 2-4). Bristol, Buffalo, UK \& Toronto, Canada: Multilingual Matters.

Paris, S. G., Cross, D. R., \& Lipson, M.Y.(1984). Informed strategies for learning: A program to improve children's reading awareness and comprehension. Journal of Educational Psychology, 76(6), 1239-1252.

Robson, C. (2002). Real world research: A resource for social scientists and practitioner-researchers (2nd ed.). Malden, MA: Blackwell Publishing.

Schmitt, M. C. (1990). A questionnaire to measure children's awareness of strategic reading processes. The Reading Teacher, 43(7), 454-461.
Singleton, D. (2014). Is there a best age for learning a second language? In V. Cook \& D. Singleton (Eds.), Key Topics in Second Language Acquisition (pp. 18-36). Bristol, Buffalo, UK \& Toronto, Canada: Multilingual Matters.

Šamo, R. (2009). The age factor and L2 reading strategies. In M. Nikolov (Ed.), Early Learning of Modern Foreign Languages: Processes and Outcomes (pp. 121-131). Bristol, Buffalo, UK \& Toronto, Canada: Multilingual Matters.

Šamo, R. (2015). Receptive skills in the linguistic and non-linguistic context of EFL learning. In J. Mihaljević Djigunović \& M. Medved Krajnović (Eds.), Early Learning and Teaching of English: New Dynamics of Primary English (pp. 174-190). Bristol, Buffalo, UK \& Toronto, Canada: Multilingual Matters.

Tracey, H. D., \& Mandel Morrow, L. (2006). Lenses on reading: An introduction to theories and models. New York, NY \& London, UK: The Guilford Press.

Vilke, M. (2015). The Context. In J. Mihaljević Djigunović (Ed.), Children and English as a foreign language (pp. 13-29). Zagreb, Croatia: FF press.

Vygotsky, L. (2012). Thought and language (revised and expanded ed.). Cambridge, MA \& London, UK: The MIT Press.

Wei, L., \& Moyer, M. G. (Eds.). (2008). The Blackwell guide to research methods in bilingualism and multilingualism. Malden, MA: Blackwell Publishing.

Yu-Fen, Y. (2002). Reassessing readers' comprehension monitoring. Reading in a Foreign Language, 14, 1. Retrieved from http://nflrc.hawaii.edu/rfl/ April2002/yang/yang.html 